\title{
The welded CNC machine tool frame
}

\author{
Piotr Boral ${ }^{1, *}$, Tadeusz Nieszporek ${ }^{1}$, Rafał Gołębski ${ }^{1}$ \\ ${ }^{1}$ Czestochowa University of Technology, Institute of Mechanical Technologies, Al. Armii Krajowej \\ 21, 42-201 Czestochowa, Poland
}

\begin{abstract}
Machine tools are built based on cast-iron bodies. Cast iron well dumps down vibrations and is dimensionally stable. Therefore, many conventional machine tools are modernized and modified into CNC machine tools based on the seasoned old bodies of those machine tools. Nevertheless, CNC machine tools are also manufactured based on polymer concrete, which vibration damping ability is even better. On the other hand, attempts made in the past by leading machine tool manufacturers to use welded frames in $\mathrm{CNC}$ machine tools failed. The revival of interest in welded frames was spurred by economic considerations, as steel systems are much thinner compared to cast-iron ones. They are able to carry the same loads. The construction of $\mathrm{CNC}$ machine tools with a welded steel frame undertaken at the Institute of Mechanical Technologies (ITM) of the Czestochowa University of Technology is an attempt to solve this constructional problem. The machine tool frame was designed with use of CAD solid works system. The ultimate success of using the welded frame is determined not only by the frame itself, but also generally the design of the machine tool and its operation parameters. The welded frame was used for a high-accuracy three-axis milling machine. In this respect, it is equal of professional machine tools manufactured by reputed companies. It can be either a production machine tool or a test stand.
\end{abstract}

Keywords: machine tools, the welded frame

\section{Introduction}

Conventional machine tools and, generally, also CNC (Computer Numerical Control) machine tools are manufactured based on cast frames of either grey engineering cast iron or modified (malleable or nodular) cast iron [1]. Cast iron has a good vibration damping capability and is dimensionally stable, and the machine tool is rigid and accurate. For these reasons, many conventional machine tools are modernized and modified into CNC machine tools just based on the well-seasoned old frames of such machine tools.

Nevertheless, CNC machine tools are also manufactured based on polymer concrete frames, whose vibration damping capability is even better [2] - Table I. A machine tool of this type must be very accurately levelled and statically stable, since should it breaks, the frame would be irreparable. Investigations are also being undertaken into hybrid frames that combine cast iron with a mineral casting [3]. Polymer concrete may also provide a filling of cast iron or steel machine tool frames as a vibration damping mass.

\footnotetext{
*Corresponding author: piotrek@itm.pcz.czest.pl

Reviewers: Andrej Czán, Bogdan Posiadala
} 
On the other hand, attempts made in the past, even by leading machine tool manufacturers, to use welded steel frames in CNC machine tools failed on a wider scale have so far ended in failure.

Table 1. Comparison of the properties of steel, cast iron and polymer concrete [2]

\begin{tabular}{|l|c|c|c|c|}
\hline \multicolumn{1}{|c|}{ Properties } & Units & Steel & $\begin{array}{c}\text { Grey cast } \\
\text { iron }\end{array}$ & $\begin{array}{c}\text { Polymer } \\
\text { concrete }\end{array}$ \\
\hline Density & $\mathrm{g} / \mathrm{cm}^{3}$ & 7.85 & 7.2 & $2.1-2.4$ \\
\hline Compressive strength & $\mathrm{N} / \mathrm{mm}^{2}$ & $250-1200$ & $350-450$ & $140-170$ \\
\hline Bending strength & $\mathrm{N} / \mathrm{mm}^{2}$ & $400-1600$ & $150-400$ & $25-40$ \\
\hline Young's modulus & $\mathrm{kN} / \mathrm{mm}^{2}$ & 210 & $80-120$ & $30-40$ \\
\hline Heat-transfer coefficient & $\mathrm{W} /\left(\mathrm{m}^{*} \mathrm{~K}\right)$ & 50 & 50 & $1.3-20$ \\
\hline $\begin{array}{l}\text { Thermal expansion } \\
\text { coefficient }\end{array}$ & $\mu \mathrm{m} /(\mathrm{m} * \mathrm{~K})$ & 12 & 10 & $12-20$ \\
\hline Specific heat & $\mathrm{kJ} /\left(\mathrm{kg} \mathrm{k}^{*} \mathrm{~K}\right)$ & $0.45-0.5$ & 0.5 & $0.9-1.3$ \\
\hline Logarithmic decrement & & 0.002 & 0.003 & $0.02-0.03$ \\
\hline Cost & $\mathrm{EUR} / \mathrm{dm}^{3}$ & 7.67 & 5.11 & 2.56 \\
\hline $\begin{array}{l}\text { Manufacturing energy } \\
\text { demand }\end{array}$ & $\mathrm{MJ} / \mathrm{dm}^{3}$ & 160 & 120 & 25 \\
\hline
\end{tabular}

Trials on manufacturing such machine tools are under way, since in comparison with cast frames, welded frames allow a twofold reduction of their weight with the same rigidity of the frame (the module of elasticity of steel is 1.8-2.4 times greater than that of cast iron) [4]. For example, a special welded-frame machine tool, Millturn M100, intended for the production of worms is manufactured by Austria's WFL company. Extrusion machines designed for the processing of large-molecular plastics require worms of a length of up to $6500 \mathrm{~mm}$ to be used. The company PROMUS of Czestochowa has made a welded grinder frame for the company JOTES of Lodz. This is a machine tool frame with the required high accuracy and dimensional stability. PROMUS of Czestochowa has also made about eighty welded machine frames for a German customer [5].

The construction of a CNC machine tool with a welded steel frame, undertaken at the Institute of Mechanical Technologies (ITM) of the Czestochowa University of Technology, is another attempt to solve this problem. The ultimate constructional success is determined not only by the building of the frame itself, but, in general, also by the design of the machine tool and its operation parameters. On the assumption, this is a three-axis CNC milling machine with high accuracy, in this respect being the equal of professional machine tools manufactured by reputed companies. It will be a production machine tool and, at the same time, a test stand. The machine tool is to be designed for manufacturing geometrically complex parts by the Step-by-Step (SbS) method using a small-diameter cylindrical mill. The machine tool is now under construction. The reason for the manufacturer's interest in frames of this type are economic considerations.

For their casting, cast frames require wooden patterns, which are used for manufacturing several dozen castings and are very expensive (the price of a pattern is comparable to that of the frame). Therefore, in the case of building a single machine tool and making one frame, this technology was considered economically unjustified. For this reason, it was decided on a welded machine tool frame. All machine tools with a cast frame based on the same pattern belong to the same type series. By contrast, welded frame machine tools may be different in terms of the table size and the magnitude of displacements along individual axes, as needed, which can be an asset of this technology. This is important especially in the automation of production and building of production lines composed of several specially designed machine tools. 


\section{Machine tool development trends}

Contemporary $\mathrm{CNC}$ machine tools differ significantly from conventional machine tools Fig. 1.

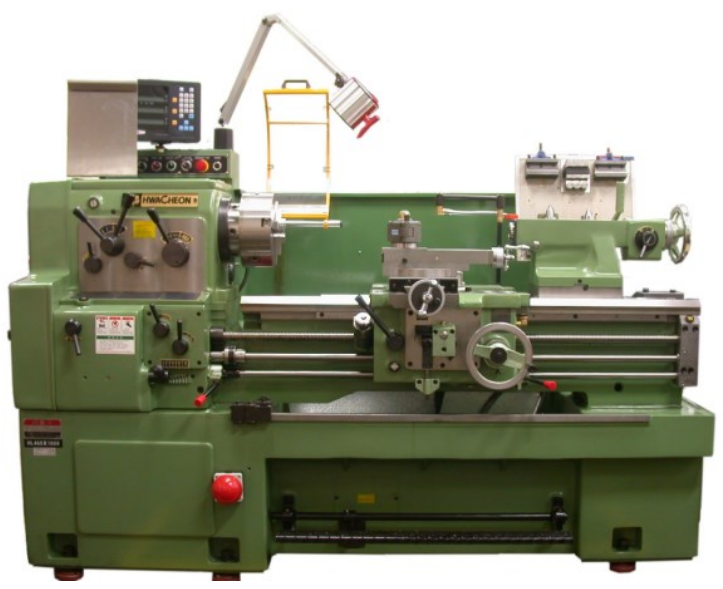

Fig. 1. A conventional machine tool

Above all, conventional machine tools have one main drive, which is cinematically and mechanically linked with all axes [6], and have no tool stores [7]. In conventional machine tools there is a clear division into turning lathes, milling machines, grinding machines, gear machining machine tools, slotting machines, etc. For CNC machine tools, this division is increasingly difficult, especially in the case of multi-axis machine tools. For example, the QTN (Quick Turn Nexus) MSY lathe by MAZAK is equipped with a turret with driven tools situated in the axial and radial directions, thus featuring milling functions [8] - Fig. 2.

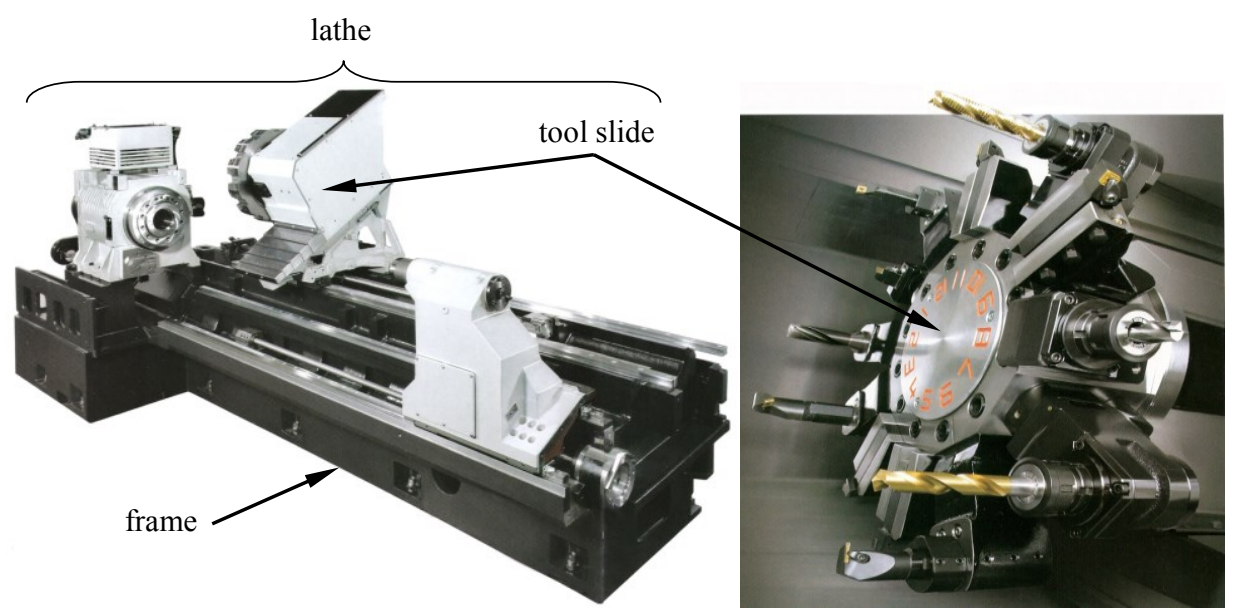

Fig. 2. A QTN turning centre: frame, tool slide, lathe

In addition, it has the capability to control and displace the tool slide in the Y axis. The $\mathrm{C}$ axis of the workpiece spindle is also controlled and an intercepting spindle can be situated on the opposite side, while the rotations of both spindles can be synchronized, which allows the workpiece to be fixed in the other spindle and being machined on the other side without having to switch off the rotations. This increases the productivity and 
accuracy of machining, which corresponds to the Do-In-One idea - machining a workpiece in a single fixture on one machine - which has been promoting by MAZAK for years.

During machine tool operation, chips are transferred with a conveyor to the outside at the side of the machine tool. In turn, a special arm intercepts machined small workpieces and throws them into a container in front of the machine tool. The main workpiece spindle has normally a clearance, which enables the use of a feeder and machining of a bar in an automatic cycle. Thus, the machine tool can operate, for instance, through the whole shift without the operator's intervention. The machine tool can operate with a robot, and is furnished with special functions for this purpose. The machine tool's working space is closed, which enables intensive cooling with cooling and lubricating liquid or with oil mist. For cleaning the machine tool, the spindles and the slide, compressed air is used. The control systems enables the programming of sub-micrometric $0.0001[\mathrm{~mm}]$ feeds and the workpiece spindle rotation angle with an accuracy of 0.0001 [deg]. This machine tool is classified as a turning centre.

In CNC machine tools, some manufacturers employ their own control systems. For example, the MAZAK company uses the universal MAZATROL MATRIX CAM control system [9]. There is a very large number of machine tool manufacturing companies worldwide, therefore control systems such as SINUMERIC [10], FANUC [11] and HaidenHein are commonly used [12]. These are universal control systems with great capabilities and a wide range of applications in different machine tool types. Generally, machine tools are sold with the basic version of control systems, and their possible expansion by additional modules and functions involves added, often high costs. The capability of machine tools to operate in a local ETHERNET network and to be programmed off-line enables their programming using CAD/CAM systems. All contemporary control systems practically operate in the WINDOWS environment, thanks to which the interface is user-friendly, which makes the operation and programming of the machine tool easy.

With the development of CNC machine tools and tooling, an intensive development of CAD/CAM (Computer Aided Design/Computer Aided Manufacturing) and control systems follows. Programs, such as CATIA [13], EdgeCAM [14], SolidWorks [15], MasterCAM [16] and others enable the 3D solid design of parts, generation of 2D working drawings, simulation of the machine operation kinematics, MES strength analysis, as well as 3D machining simulation and the generation of the CNC machine tool control code.

The advantage of these solutions lies in the fact that, although the writing of a machine tool control program for machining a simple part on a three-axis machine tool in either a dialogue system or manually in $\mathrm{G}$ codes is possible, the writing of a program for machining a geometrically complex part requiring a five-axis machine tool for its machining is very difficult, if not impossible, without special software.

\section{The three-axis CNC milling machine}

The design of the milling machine (see Fig. 3) was developed by using the SolidWorks program. This is a three-axis milling machine of a welded construction from S355J2 steel plates. The core of the solution lies, among other things, in the use of a high-speed tool spindle with a rotational speed of $18000 \mathrm{rpm}$. In conventional machine tools, the spindle rotational speed is low; for example, for the Heckert FSS $400 \mathrm{VI} / 2$ vertical milling machine, it is $1400 \mathrm{rpm}$ [17]. At a low spindle rotational speed in machining with a multiblade mill, especially a large-diameter one, an impact character of tool blade operation occurs, which results in considerable vibrations. In the adopted milling machine design, at a low spindle rotational speed and a small mill diameter, this phenomenon will not occur. 
The welded frame is made from $20 \mathrm{~mm}$-thick plates and is densely ribbed, which imparts it high rigidity - Fig. 4.

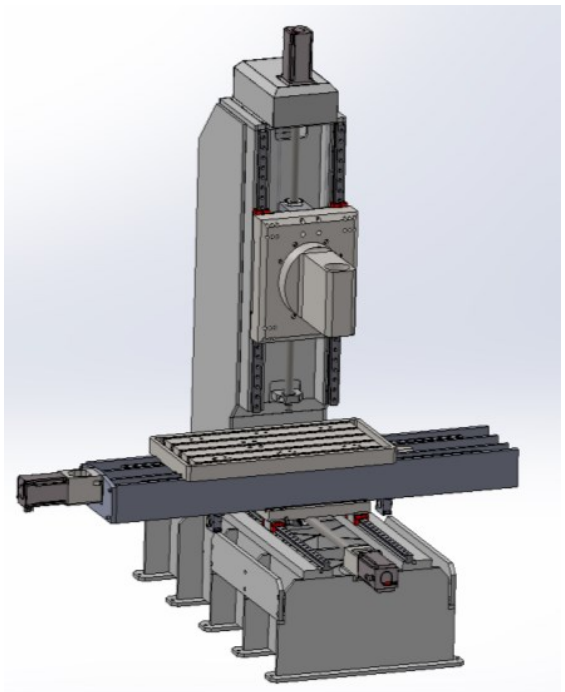

Fig. 3. The design of the XYZ CNC milling machine

The frame was constructed of enhanced-strength steel S355J2. It was made by the MAG method employing the following welding parameters: current intensity - welding currents, 280 - $290 \mathrm{~A}$; voltage, 26V; $1.2 \mathrm{~mm}$-diameter wire in grade G4Si1. V and X-type grooves were designed for making welds, depending on the access to them. In the future, for similar solutions, robotized welding with off-line programming assisting can be used [18]. If further design and technological changes are made, it will be possible to reduce the mass by employing other welded materials [19] and more accurate weld dimensioning [20]. The analysis of the above-mentioned activities and the industrial implementation of the frame under discussion may lead to further engineering \& design changes, similarly as for the nodes described in work [21].

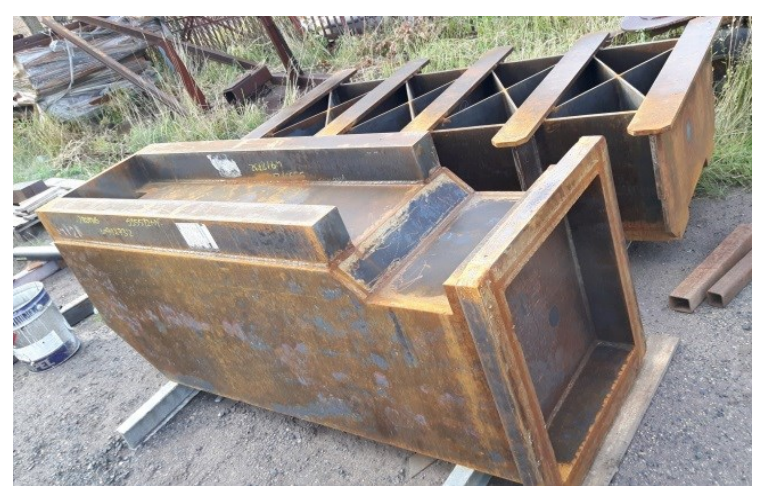

Fig. 4. Machine tool pillars and bases during seasoning

The welds were examined for the correctness of execution by an ultrasonic method using a KRAUTKRAMER USM 35XS no. 14374a flaw detector (with wallpaper glue being used as a coupling agent). 
The frame was subjected to vibration stress relieving. The vibration was carried out using a WIBROPOL VM120 set with a VC220 vibrator.

The deformation of the frame base after stress relieving over a length of $2 \mathrm{~m}$ amounted to $5 \mathrm{~mm}(0.25 \%)$ and was removed after machining. This result indicates a possible and effective reduction of welding stresses and generation of deformations that can be subsequently removed by further machining.

A similar character of operation is exhibited by welds in truck chassis frames, which are subjected to cyclic stresses. They may cause their damage in the form of fatigue cracking [22].

Using stress relieving vibration results in an advantageous reduction of peak stresses in the welds that are decisive to their fatigue strength - Fig. 5 .

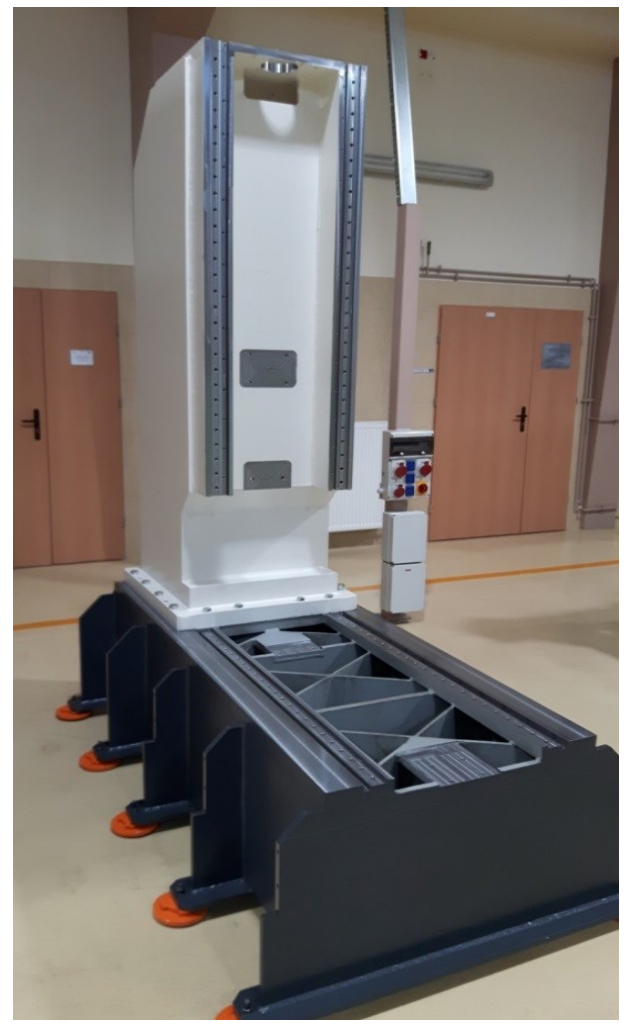

Fig. 5. The CNC milling machine frame after seasoning, vibrating and machining

The power transmission systems were based on ball screws (by Steinmeyer [23]) and prismatic guides (by Schneeberger [24]) of the highest accuracy. Three servo-drives manufactured by Beckhoff, each with a moment of $29 \mathrm{Nm}$, were employed. The control was based on the Beckhoff system with the PLC CX5010 controller, which provides the capability to control up to 100 axes and is very efficient [25]. This is a control system that is very rarely found in machine tools, which provides a great potential for being further expanded.

The system includes a CNC interface that can be modified, which is impossible in the case of other common control systems [26].

The controller has the in-built WINDOWS CE and the TwinCAT program installed [27]. To program this controller, it is sufficient to connect a monitor, a keyboard and a mouse to it (there is no need for connecting a PC), which distinguishes it from other 
controllers. The programs can be written in the TwinCAT [28] or the CoDeSys system [29], practically in 6 languages [30, 31]. Textual languages: IL - Instruction List, ST Structured Text. Graphical languages: SFC - Sequential Function Chart, FBD - Function Block Diagram, LD - Ladder Diagram, CFC - Continuous Function Chart. It is a fully professional CNC machine tool.

The constructed machine tool will be the subject of further investigation. It will also be both a test stand and a production machine tool.

\section{Conclusions}

The stresses and deformations of a frame after welding can be effectively removed by seasoning and vibrating followed by machining. The above-mentioned operations are especially important for new-generation machine tools, such as CNC machine tools with three and more axes.

The linear welding deformations, amounting to $0.25 \%$, which form due to vibration are contained within machining allowances and can be foreseen by the designer.

The welded frame construction discussed in the present study can be used for similar applications in numerically controlled machine tools, as well as for other engineering purposes.

\section{References}

1. A. Łukomski, The frames of machines and equipment, Part 1. Des. Eng. Cons. 93, (2015)

2. E. Baumeister, Hohlkugelkomposit - Characterization of thermal and mechanical properties of a new lightweight construction material. (Doctoral dissertation. Magdeburg 2004)

3. N. Kępczak, W. Pawłowski, Theoretical research of dynamic properties of machine tool bodies made of cast iron and hybrid connection of cast iron and mineral cast. Mech. 8/9, 177-203F (2015)

4. A. Łukomski, The frames of machines and equipment, Part 2. Design. Eng. Constr. 94/95, (2015)

5. http://www.promus.pl/index.html

6. J. Honczarenko, Numerically controlled machine tools. (WNT, Warsaw, 2008)

7. P. Cichosz, Cutting tools. (WNT, Warsaw, 2009)

8. Mazak, Quick Turn Nexus 250-II MSY. https://www.mazakusa.com/machines

9. Mazak, MazaCAM - Mazak Mazatrol Programming System. http://www.mazacam.com

10. Siemens, Numerical control SiNUMERIC - Siemens. https://www.automatyka.siemens.pl/solutionandproducts_dt/845.htm (2011)

11. FANUC, Programming of machine tools Fanuc, FANUC seria 16i-TB FANUC seria 18i-TB FANUC seria 160i-TB FANUC seria 180i-TB, User's Guide. (2002)

12. Heidenhain, User's Manulal. Conversational Programming TNC 406 TNC 416 NC Software. (2001)

13. J. Pobożniak, Programming numerically controlled machine tools in the CAD/CAM CATIA V5 system. (Helion, Gliwice, 2014)

14. P. Kochan, Edgecam. Multi-axial CNC milling. (Helion, Gliwice, 2014) 
15. J. Domański, SolidWorks 2014. Designs of machines and structures. Practical examples. (Helion, Gliwice, 2015)

16. P. Niesłony, Basics of programming CNC machine in CAD/CAM system - Mastercam. (Helion, Gliwice, 2012)

17. Fritz Heckert, Heckert FSS 400 VI/2 vertical milling machine. Technical documentation

18. M. Nowak, J. Buchowski, D. Wiśniewski, Robot montioned large structures welding with off-line support programing. Wel. Tech. Rev. 85, 19-28 (2013)

19. Z. Mirski, Z. Fałek, Welded containers for scrap and debris transport of 450 Hardox steel. Wel. Tech. Rev. 87, 5-9 (2015)

20. K. Kudła, K. Wojsyk, Method for analytical computation of stresses in fillet joints for complex load states - according to eurocode 3. Wel. Tech. Rev. 86, 8-14 (2014)

21. T. Urbański, Hybrid node - predictions of transverse shrinkage in butt join on the basis of twodimensional designed experiment. Wel. Tech. Rev. 87, 22-26 (2015)

22. J. Słania, Ł Kuk, Process of joining materials to build vehicles and motor-car bodies in the automotive industry. Wel. Tech. Rev. 86, 40-46 (2014)

23. Steinmeyer, Ball scrwe drives. Welcome to whete precision is. www.steinmeyer.com

24. Schneeberger, MONORAIL and AMS. Profiled linear guideways and integrated measuring systems. (2015)

25. Beckhoff, Beckhoff TwinCAT The Windows Control and Automation Technology PC Control Introduction Beckhoff. http:www.beckhoff.com/twincat, (2001)

26. Beckhoff, Beckoff New Automation Technology TwinCAT 3. Beckhoff, Brian McClure, http:www.beckhoff.com/twincat, (2013)

27. Beckhoff, Basics of program handling TwinCAT System Manager Part 1. docplayer.pl, (Warszawa, 2009)

28. Beckhoff, Basics of program handling TwinCAT PLC Control Part 2. docplayer.pl, (Warszawa, 2009)

29. Moeller, User's Guide, Programming PLCs in CoDeSys 2.3. www.moeller.pl/ Documentation/Literatura/h1437pl.pdf, 3S - Smart Software Solutions GMBH, (2006)

30. Moeller, Programming PLCs in easy Soft CoDeSys. (2010)

31. Moeller, Easy Soft environment - CoDeSys. www.moeller.pl (2015) 